\title{
Valoración turística del patrimonio cultural inmaterial
}

\author{
Tourist valuation of intangible cultural patrimony
}

\author{
Amed Said Uceda Mercado \\ asaid.um.90@gmail.com \\ https://orcid.org/0000-0003-4236-3208 \\ Instituto Técnico CEC, Oruro-Bolivia
}

Artículo recibido en enero 2021 / Arbitrado en marzo 2021 / Aceptado en mayo 2021 / Publicado en julio 2021

RESUMEN El objetivo de este artículo fue determinar las causas que afectan la valoración del Patrimonio Cultural Inmaterial (PCI) como atractivo turístico. Se trata de una investigación con enfoque sociocrítico que tomó como objeto de estudio la zona del cementerio de la ciudad de La Paz, Bolivia. La recolección de información se realizó con base en revisión bibliográfica, observación participante, consultas a la población y criterio de expertos. Como resultado se determinaron cinco causas que afectan la valoración del PCI de la zona: desorden, inseguridad ciudadana, comercio de productos ajenos a la región, falta de higiene y falta de educación turística.

Se concluye que las expresiones culturales de la zona - comida, bebida, vestimenta, joyería de oro y plata, artes, fiestas y música - son atractivos turísticos poco valorados actualmente, pero mediante gestiones que favorezcan su preservación pueden constituirse en recursos turísticos importantes. Estas gestiones deben incluir la participación conjunta de la población, instituciones públicas e instituciones privadas.

Palabras clave: Patrimonio cultural; Expresiones culturales; Patrimonio intangible; Turismo cultural; Atractivo turístico

ABSTRACT The objective of this article was to determine the causes that affect the valuation of the Intangible Cultural Heritage $(\mathrm{ICH})$ as a tourist attraction. It is an investigation with a socio-critical approach that took as its object of study the area of the cemetery of La Paz, Bolivia. The information collection was carried out based on bibliographic review, participant observation, consultations with the population and expert judgment. As a result, five causes that affect the evaluation of the $\mathrm{PCl}$ of the area were determined: disorder, citizen insecurity, trade in products from outside the region, lack of hygiene and lack of tourism education.

It is concluded that the cultural expressions of the area - food, drink, clothing, gold and silver jewelry, arts, parties and music - are currently undervalued tourist attractions, but through efforts that favor their preservation they can become important tourist resources. These steps must include the joint participation of the population, public institutions and private institutions.

Key words: Cultural heritage; Cultural expressions; Intangible heritage; Cultural tourism; Tourist attraction 


\section{INTRODUCCIÓN}

Como se señala en Hosteltur (2007), un activo intangible es una percepción subjetiva; su preservación depende de la toma de conciencia de la identidad de la urbe por los ciudadanos. El Patrimonio Cultural Inmaterial $(\mathrm{PCl})$ es un importante factor para el mantenimiento de la diversidad cultural frente a la globalización. Contribuye al diálogo entre culturas y promueve el respeto hacia otros modos de vida, reúne conocimiento y técnicas que se transmiten de generación en generación. El valor social y económico de esta transmisión es pertinente en grupos sociales minoritarios y mayoritarios de países en desarrollo y desarrollados. El PCI es tradicional y contemporáneo, integrador, representativo y está basado en la comunidad (Cajías, 2016).

Según la Organización de las Naciones Unidas para la Educación, la Ciencia y la Cultura (UNESCO), el PCI no incluye jerarquías y se manifiesta en: tradiciones y expresiones orales, incluido el idioma como vector del patrimonio cultural inmaterial; artes escénicas y del espectáculo; usos sociales, rituales y actos festivos; conocimientos y usos relacionados con la naturaleza y el universo; técnicas artesanales tradicionales. Muchas de estas manifestaciones son atractivos turísticos, es decir, pueden generar en los turistas el deseo de conocer y experimentar (Navarro, 2015).

Bolivia se caracteriza por tener diversidad de culturas y gran cantidad de atractivos turísticos materiales e inmateriales. Sin embargo, la protección del $\mathrm{PCl}$ recibe poca importancia, provocando tergiversación, apropiación indebida y desconocimiento de la población (Paredes, 2012). Particularmente, la ciudad de La Paz tiene diversas manifestaciones culturales materiales e inmateriales, no obstante, el turismo se ve afectado por el desorden y la inseguridad ciudadana (Paredes, 2012). Este estudio se enfoca específicamente en una zona de esta ciudad, la zona del cementerio. El PCl de esta zona es amplio y muestra expresiones culturales con valor turístico, sin embargo, estos recursos inmateriales no son utilizados como recursos turísticos. Así como en otras zonas de la ciudad, el comercio y la mentalidad de la población son algunos de los factores que están afectando la actividad turística y la preservación del $\mathrm{PCl}$.

El objetivo de la investigación fue determinar las causas que afectan la valoración del $\mathrm{PCl}$ como atractivo turístico. Con este fin primero se caracterizó el PCI de la zona; segundo, se identificó la percepción de la población sobre el $\mathrm{PCl}$ y su valoración como atractivo turístico; finalmente, se consultó el criterio de expertos para analizar la problemática y detectar las posibles causas.

La pertinencia de esta investigación es clara, el análisis que se presenta identifica, en un contexto particular, la problemática que obstaculiza la preservación del $\mathrm{PCl}$ y su tratamiento como atractivo turístico en Bolivia.

\section{MÉTODO}

Se trata de un estudio con enfoque sociocrítico que se enfocó en determinar las causas que afectan la valoración del $\mathrm{PCl}$ como atractivo turístico, tomando como objeto de estudio la zona del cementerio de la ciudad de La Paz, Bolivia. Esta zona incluye la subzona Garita de Lima y los barrios El Tejar y Bajo Tejar. Si bien el diseño metodológico tiene corte transversal, la recolección de información se realizó en tres etapas.

Primero, mediante revisión bibliográfica y observación participante, se caracterizó el $\mathrm{PCl}$ de la zona, identificando las principales tradiciones y expresiones orales, artes, usos sociales, rituales y actos festivos.

Segundo, se consultó a tres grupos de la población su percepción sobre el $\mathrm{PCl}$ y su valoración como atractivo turístico. Los dos primeros grupos fueron seleccionados mediante 
muestreo probabilístico aleatorio simple y el tercer grupo estuvo constituido por cinco expertos (los criterios de selección se detallan más adelante). En todos los casos se aplicó un mismo cuestionario que contiene once preguntas, de las cuales nueve son cerradas y dos abiertas. El primer grupo está constituido por la población mayor de edad de la ciudad de La Paz que conoce la zona (para identificar al grupo objetivo se incluyó una primera pregunta de cohorte); el segundo grupo se enfocó en consultar la percepción de las personas mayores de edad que viven o trabajan en la zona; finalmente, el tercer grupo estuvo conformado por expertos en la temática. En el grupo uno se consultó a 381 personas y en el grupo dos a 185.

Tercero, se analizó la problemática bajo el criterio de expertos, detectando así cinco principales causas. Los criterios de selección de los cinco profesionales consultados fueron más de 15 años de experiencia en gestión de turismo cultural, investigadores activos en $\mathrm{PCl}$ de la ciudad de La Paz o historia específica de la zona del cementerio.

\section{RESULTADOS}

La zona del Cementerio General de La Paz está conformada por los barrios El Tejar y Bajo Tejar, ambos pertenecientes al Macrodistrito 13 ubicado al noroeste de la ciudad, conocido también como Macrodistrito Max Paredes. Su historia se remonta a Churubamba o San Sebastián, los nombres con los que se conocía la ladera oeste de la ciudad, separada por el río Choqueyapu.

En palabras de Cajías, "Churubamba es el ombligo de la ciudad [...] desde hace más de 500 años, cuando estaba habitada por aymaras del señorío Pacajes y regida por el poder de los incas, y ahora convertida en un dinámico centro de actividad comercial” (2010, p. 2). Está ubicada en el límite entre los barrios indios de la ciudad y los barrios económicamente más valorados. Las edificaciones modernas están entremezcladas con casas coloniales y otras estructuras republicanas del pasado siglo. Se ha convertido en un centro empresarial que además tiene mercados populares, escuelas y centros deportivos. Sin embargo, la herencia indígena y su cultura permanecen, pudiéndose observar una vitalidad mestiza y tradicional que perduran al lado de las nuevas expresiones culturales modernas. El espacio público de la zona causa recelo respecto al sistema de los espacios públicos ocupados por comerciantes.

Como menciona Pereira (2006), las discusiones sobre espacio público son parte del debate entre las relaciones naturaleza-sociedad. La población adopta diferentes formas de vida de acuerdo con sus condiciones económicas y socioculturales, estas pueden considerarse como estrategias para su subsistencia (Quesada, 2006). En algunos casos, la adopción del espacio urbano de forma libre y ligada a un comercio más abierto al público provoca desorden territorial evidente y relacionado con los usos y costumbres propios.

La fundación del Cementerio General de La Paz data de comienzos del siglo XIX, tras la autorización de la construcción de cementerios delimitados bajo muros en 1826, el 24 de enero de 1831 se decretó su construcción en un terreno de 30 hectáreas. A la fecha se han hecho algunas mejoras como la planimetría del terreno que le otorgó un orden interno, es el Arco del Triunfo el elemento más característico de la ciudad, fue construido en 1835 con estilo neoclásico y 14 metros de altura. Representaría la gloria de entrar en el reino del Señor (GAMLP, 2013). 
Figura 1. Puerta principal del Cementerio General de La Paz.

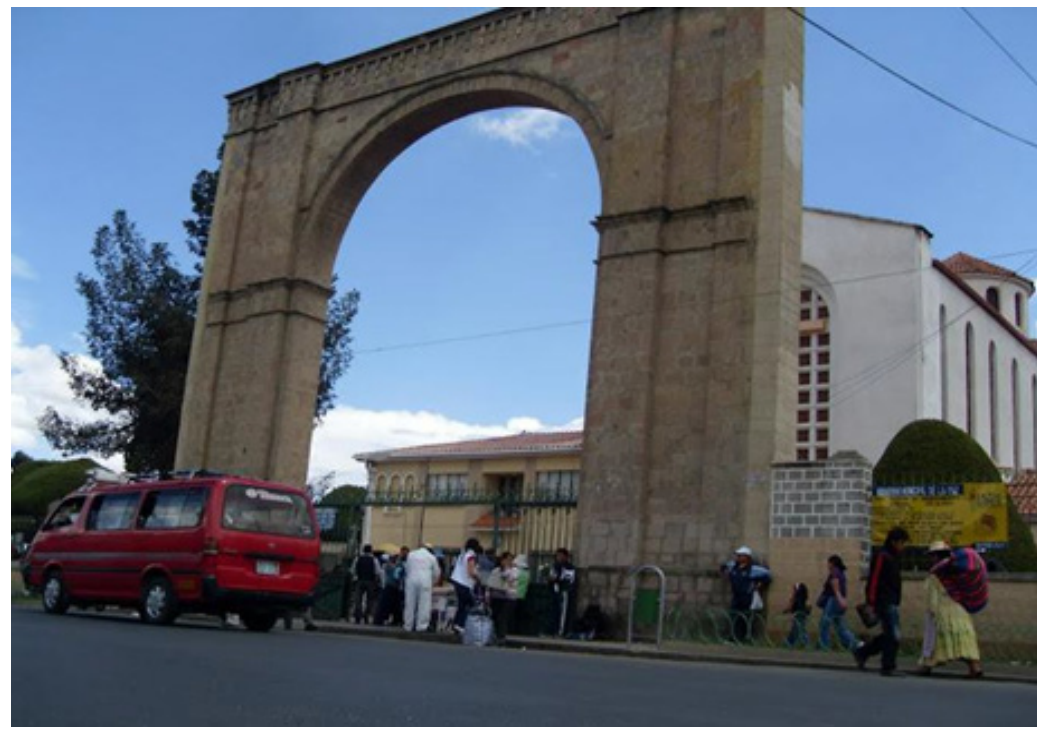

Fuente: Bolivia Fundación (2014)

Para abordar el tema de manera ordenada se describirá la zona del Cementerio de sur a norte en términos geográficos: primero la subzona Garita de Lima; segundo el barrio Bajo Tejar y; finalmente el barrio El Tejar. La Garita de Lima que históricamente fue sede de levantamientos y lucha de los pueblos, ahora es una zona de comercio, no obstante, también es considerada como una zona «negra» por el crecimiento de la delincuencia y el consumo de alcohol (GAMLP, 2009).

El barrio Bajo Tejar fue constituido gracias a la Reforma Urbana en 1960, se extiende desde la Entre Ríos, pasando por la Kollasuyo, el Cementerio y llegando a Yacimientos. El nombre se debe a que en ese entonces existían fábricas de tejas en la zona, en esa época el cementerio carecía de muros limítrofes, era frecuente ver entierros en el suelo; surgían cuentos que se han convertido chistes y leyendas. Entre sus expresiones culturales más reconocidas a través de los años está la danza de los Ch'utas fundada en 1928, bajo la comparsa “Siempre Aljeris de La Paz" (GAMLP, 2009).

El barrio El Tejar es el centro del movimiento comercial de la zona. Se constituyó entre 1960 y 1964, en esa época cuando el carnaval se celebraba con mayor intensidad, podía suceder que los ch'utas que se extraviaban aparezcan muertos en la cancha El Tejar. Actualmente la principal actividad cultural es la fiesta en honor al Señor de la Exaltación, celebrada cada 14 de septiembre y en la que participan alrededor de 40 comparsas. También destacan las actividades con la parroquia El Salvador, las fiestas son semanales y entradas folklóricas son un atractivo importante en la ciudad de La Paz (GAMLP, 2009).

\section{Expresiones culturales}

Para la UNESCO (2005), las expresiones culturales son aquellas expresiones que se generan a partir de la creatividad de las personas, grupos y sociedades, y que poseen un contenido cultural

El Cementerio General es parte del patrimonio material arquitectónico de la ciudad de La Paz y diariamente recibe cientos de visitantes (Agencia de Noticias Fides, 2019). Los turistas nacionales e internaciones valoran sus características culturales, físicas e históricas. Se describen a continuación estas expresiones culturales. 
Día de Todos Santos, son dos días al año dedicados a recordar a los difuntos, tiempo de «encuentro con las almas». Las familias se reúnen cada 1 y 2 de noviembre para recibir la visita de sus difuntos, en casas y en el cementerio. La semana previa las personas visitan el cementerio para preparar los nichos. Según la creencia, las almas llegan a visitar sus hogares justo al medio día del primer día de noviembre, para recibirlas se prepara una "mesa de alma" con alimentos y bebidas que al difunto le gustaba, además de frutas y t'anta wawas, que son la representación del difunto hecha de pan; los mercados se abastecen y son altamente visitados. En las afueras del Cementerio General, en la zona popular de las calles Buenos Aires, Max Paredes y Baptista y la plaza Garita de Lima, se venden ofrendas diversas, como maicillos, galletas, dulces, empanadas, banderines y coronas (GAMLP, 2013). El segundo día de noviembre las almas son despedidas de los hogares, se recoge la mesa armada y se asiste al cementerio para preparar los altares con todos los elementos usados el primer día. El ritual en casa y en el cementerio se acompaña con música y danza (La Época, 2019).

Figura 2. Todos Santos en el Cementerio General de La Paz.

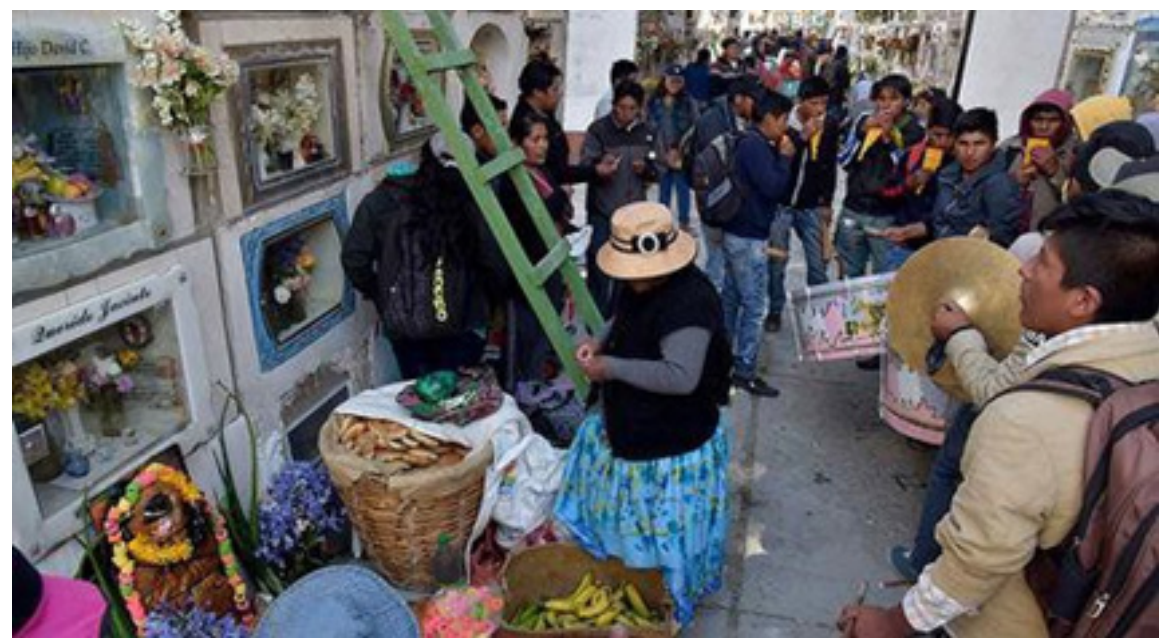

Fuente: Diario La Razón (2015)

Culto a las Natitas, el 8 de noviembre en el Cementerio General se desarrolla el Culto a las Ñatitas. Las Ñatitas son cráneos que representan a un ajayu (alma), es tratado con respeto, fe y veneración. Aunque esta celebración es vista con malos ojos por la iglesia católica, las personas que creen y gustan de esta expresión devota son quienes han hecho que el culto a una imagen ósea sea popular (Salazar, 2018).

Como otras festividades en La Paz, esta celebración conlleva a la realización de «prestes de fe» en modalidad anual rotatoria: comprende la preparación de «veladas» antes de la fiesta, que se llevan a cabo cada lunes con ex pasantes e invitados que rinden honores llevándole cigarros, coca, flores, velas y recitando oraciones para que la calavera cuide la casa contra robos y les ayude en su negocio (GAMLP, 2013). El 8 de noviembre desde las nueve de la mañana, una multitud de gente creyente se aproxima a la capilla ubicada en interiores del Cementerio General, esperando ingresar en ella y recibir la bendición divina del sacerdote. Las personas llevan a sus calaveras en urnas, adornando sus cráneos con coronas de flores, el culto dura aproximadamente ocho horas, con flores, velas, cigarros y música. Después se pasa el preste, es decir, otra familia deberá asumir la responsabilidad de organizar una fiesta en honor a la Ñatita, con alegría, local, comida, orquesta, baile y bebida (GAMLP, 2013). 
Figura 3. Las Ñatitas siendo veneradas en el Cementerio General de La Paz.

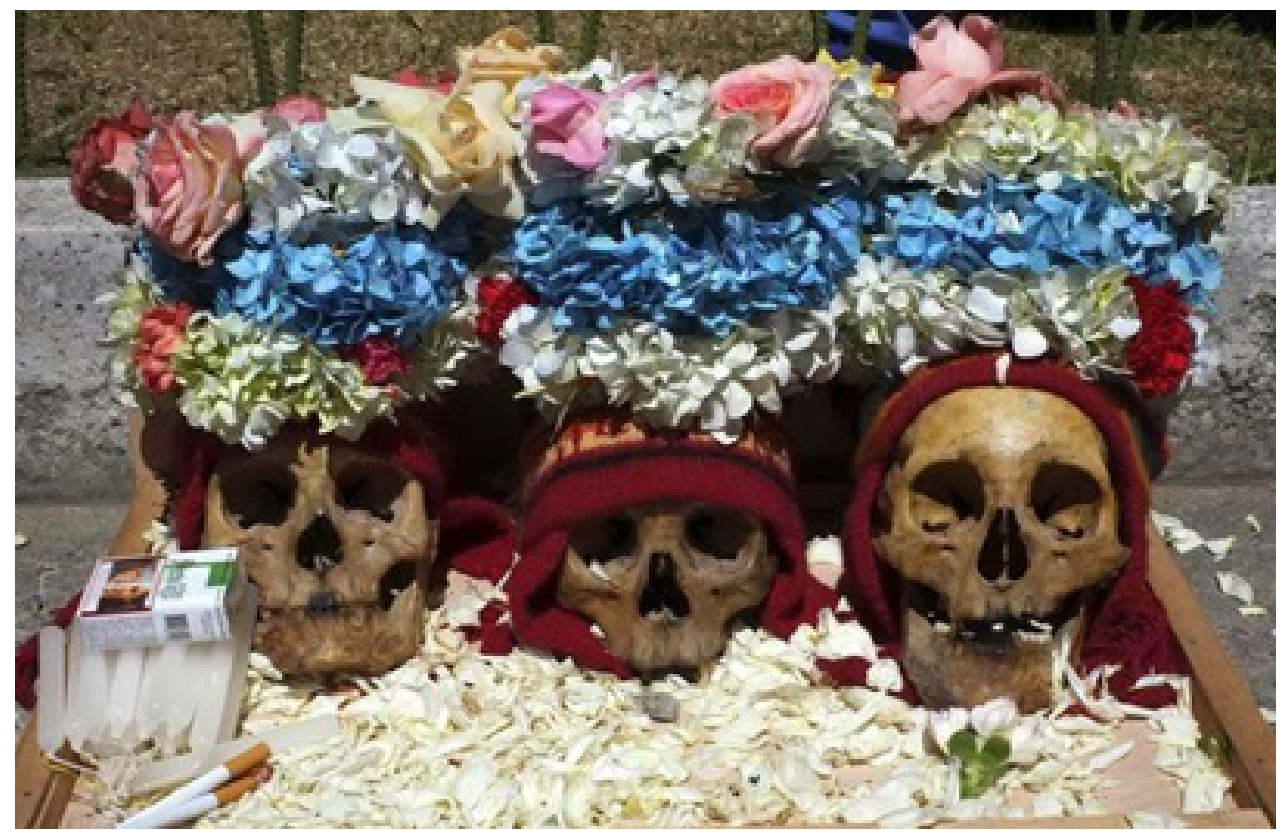

Fuente: REUTERS (s.f.)

Desentierro y entierro del Pepino, El cementerio general también es el lugar para la celebración del "Anata-Carnaval", festejo que se lleva a cabo con el desentierro y entierro del pepino. Esta tradición es una precarnavalera creada por la comparsa de ch'utas "Los Fanáticos" el año 2003. Consiste en que una comitiva festiva ingresa al cementerio para sacar el ataúd del Pepino, se lo llevan y lo hacen resucitar en un acto teatral muy alegre (GAMLP, 283).

Figura 4. Gente despidiendo al Pepino hasta el próximo Carnaval.

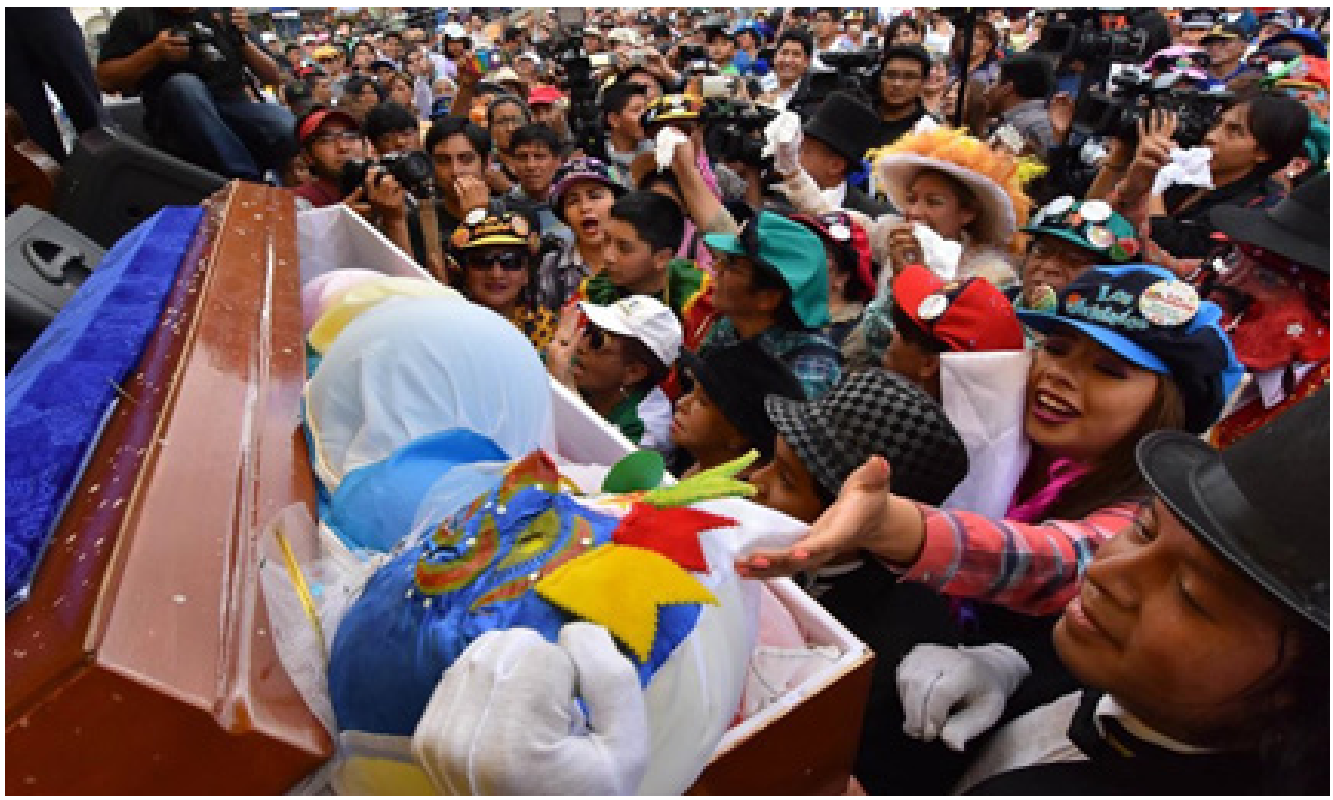

Fuente: Agencia de Noticias Fides (2019) 
Finalizando el Carnaval, en el domingo de tentación, se entierra al Pepino, acto simbólico en el que se reúnen cientos de personas en alrededores del cementerio y la avenida Baptista, llevando en brazos el ataúd. Entre llantos burlescos se entierra simbólicamente el Pepino ingresando al cementerio y con esto finaliza el carnaval (Urgentebo, 2017).

Comida y vestimenta, las expresiones culturales no se limitan a las fiestas y celebraciones, también se refieren al estilo de vida de las personas (Molano, 2007). La comida típica en la zona está disponible en los mercados populares y pequeños restaurantes. En el mercado de pescados (feria de pescado), que está ubicado entre las avenidas Héroes del Pacífico y Kollasuyo, se comercializa el típico plato de pescado. Es una calle escondida que, si bien es conocida por los lugareños, no lo es por los turistas.

Asimismo, a lo largo de la ya mencionada avenida Kollasuyo, se concentran galerías que comercializan vestimenta para chola: mantas, polleras, enaguas, sombreros borsalinos, tocados, topos y joyas para adornar la vestimenta de la mujer de pollera. De igual manera, la avenida Baptista expone trajes de danzas típicas de la región, como la Morenada, los Caporales y, en época de Carnavales, para Ch'utas y Pepinos (son trajes para rentar). En esta zona se desarrollan actividades folklóricas semanalmente, lo que la convierte en un centro cultural al aire libre que exhibe los trajes y la música típica, particularmente para la Morenada y los Ch'utas. En términos generales las vestimentas típocas de La Paz disponibles en la zona son: polleras de chola, mantas de chola, sombreros dorsalinos, trajes de ch'uta, pepino, morenada y caporal.

Artes Tradicionales, son expresiones culturales transmitidas en elementos artesanales como esculturas, vasijas y esquelas de réquiem. Existen esculturas de mármol y yeso ornamentales pequeñas, otras más grande destinadas a los nichos mortuorios. Las vasijas de vidrio y barro que se fabrican principalmente para uso espiritual. Las esquelas son pequeñas invitaciones que se diseñan para celebrar las misas de difuntos; el primer año son en blanco y negro, y muestran su colorido a partir del segundo año del fallecimiento.

Figura 5. Lápidas en el Cementerio General de La Paz.

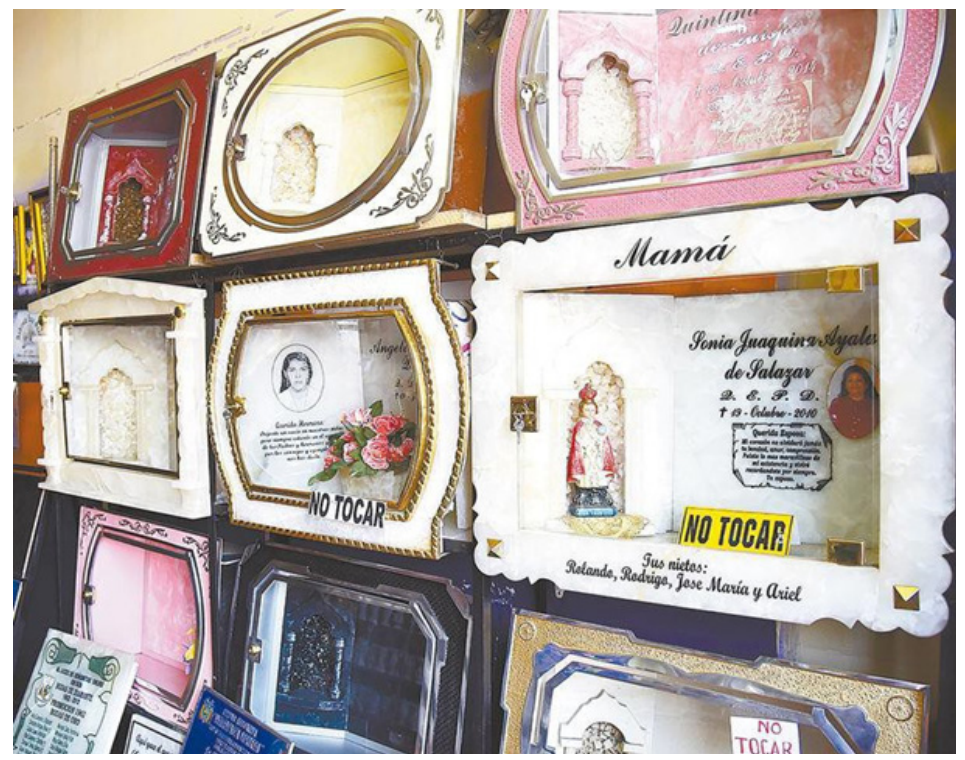

Fuente: La Razón (2015)

En la tabla 1, se presenta un listado de las principales expresiones culturales de La Paz que está presentes en la zona. 
Tabla 1. Expresiones culturales presentes en la zona del Cementerio General de La Paz.

\begin{tabular}{|c|c|c|c|c|c|}
\hline Comida y bebida & Vestimenta & $\begin{array}{c}\text { Joyería de oro y } \\
\text { plata }\end{array}$ & Artes & Fiestas & Música \\
\hline Pescado típico & Polleras de chola & Tocados & $\begin{array}{l}\text { Esculturas de } \\
\text { mármol }\end{array}$ & $\begin{array}{l}\text { Desentierro del } \\
\text { pepino }\end{array}$ & Orquestas \\
\hline Ají de fideo & Mantas de chola & Aretes & $\begin{array}{l}\text { Lápidas } \\
\text { mortuorias }\end{array}$ & $\begin{array}{l}\text { Entierro del } \\
\text { pepino }\end{array}$ & $\begin{array}{l}\text { Bandas de } \\
\text { música }\end{array}$ \\
\hline Sopa de fideo & $\begin{array}{l}\text { Sombreros } \\
\text { borsalinos }\end{array}$ & Collares & Bolsos y carteras & $\begin{array}{l}\text { Fiesta de Todos } \\
\text { Santos }\end{array}$ & $\begin{array}{l}\text { Grupos } \\
\text { folklóricos }\end{array}$ \\
\hline Chairo & $\begin{array}{l}\text { Trajes } \\
\text { (en Carnaval) }\end{array}$ & Prendedores & $\begin{array}{l}\text { Platos de } \\
\text { reconocimiento }\end{array}$ & $\begin{array}{l}\text { Fiesta de las } \\
\text { Natitas }\end{array}$ & $\begin{array}{l}\text { Música } \\
\text { autóctona }\end{array}$ \\
\hline $\begin{array}{l}\text { Fricasé de cerdo } \\
\text { / pollo }\end{array}$ & $\begin{array}{l}\text { Trajes de pepino } \\
\text { (en Carnaval) }\end{array}$ & Pulseras & $\begin{array}{l}\text { Esquelas } \\
\text { fúnebres }\end{array}$ & $\begin{array}{l}\text { Fiesta del Señor } \\
\text { de la Exaltación }\end{array}$ & $\begin{array}{l}\text { Cantos } \\
\text { populares de } \\
\text { réquiem }\end{array}$ \\
\hline $\begin{array}{l}\text { Chicharrón de } \\
\text { cerdo / pollo }\end{array}$ & $\begin{array}{l}\text { Trajes de } \\
\text { morenada }\end{array}$ & Topos & $\begin{array}{l}\text { Vasijas y } \\
\text { recipientes }\end{array}$ & $\begin{array}{l}\text { Fiesta del Gran } \\
\text { Poder }\end{array}$ & \\
\hline Wallake & $\begin{array}{l}\text { Trajes de } \\
\text { caporal }\end{array}$ & Anillos & Bordados en tela & & \\
\hline T'impu & & & $\begin{array}{l}\text { Figuras } \\
\text { religiosas de } \\
\text { yeso }\end{array}$ & & \\
\hline $\begin{array}{l}\text { Helados de } \\
\text { canela }\end{array}$ & & & $\begin{array}{l}\text { Restauración de } \\
\text { vestimenta }\end{array}$ & & \\
\hline
\end{tabular}


Tabla 2. Percepción sobre el patrimonio cultural de la zona.

\begin{tabular}{|c|c|c|c|}
\hline Ítems & $\begin{array}{c}\text { Población de } \\
\text { La Paz }\end{array}$ & $\begin{array}{l}\text { Personas que } \\
\text { viven o trabajan } \\
\text { en la zona }\end{array}$ & $\begin{array}{c}\text { Criterio de } \\
\text { expertos }\end{array}$ \\
\hline Se debe priorizar la preservación del PCI de la zona & $x$ & $x$ & $x$ \\
\hline El PCI de la zona tiene valor histórico & - & - & $x$ \\
\hline El PCI de la zona tiene valor cultural & $\mathrm{x}$ & $x$ & $x$ \\
\hline El PCI de la zona tiene valor social & $x$ & $x$ & $x$ \\
\hline Actualmente el Cementerio General es un atractivo turístico & $x$ & - & $x$ \\
\hline Actualmente la zona es un atractivo turístico & $x$ & - & $x$ \\
\hline Posición frente a potenciar el turismo en la zona & - & - & $x$ \\
\hline $\mathrm{El} \mathrm{PCl}$ de la zona es un atractivo para turistas extranjeros & - & - & $x$ \\
\hline
\end{tabular}

Según se observa en las columnas centrales de la Tabla 2, para la población paceña el PCl de la zona del cementerio: no es visto como atractivo turístico importante que pueda incrementar la actividad turística; es importante desde un punto de vista social y cultural, sin embargo, no es visto desde una perspectiva histórica-patrimonial; tiene un valor cultural importante, no obstante, este valor es insuficiente para ser atractivo; no es visto como atractivo turístico. Los motivos que expresaron los pobladores fueron desorden, inseguridad ciudadana y la poca limpieza de la zona.

El criterio de expertos es diferente (columna 4 de la Tabla 2), ellos consideran que el PCI de la zona tiene alto valor social, cultura e histórico; éste es un potenciar generador de actividad turística, sin embargo, son varios los problemas que obstaculizan este desarrollo.

Ahondando en el tema, se presenta un análisis sobre de la importancia del $\mathrm{PCl}$ en la zona del Cementerio General, recogido del criterio de expertos en la temática a nivel regional. Todos ellos coinciden en que la zona tiene riqueza cultural y patrimonial considerable que no es explotada ni valorada suficientemente. El flujo turístico en la zona del cementerio ha disminuido en los últimos años, asimismo, no existe un segmento de turistas que se dirija a hacia la zona de manera directa, los turistas pasan para dirigirse a otros destinos a través de la parada de buses cercana. Las principales causas y problemas se exponen en la Tabla 3. 
Tabla 3. Causas y problemática de la desvaloración del PCl.

\begin{tabular}{|c|c|}
\hline Causa & Problemática \\
\hline \multirow{4}{*}{ Desorden } & $\begin{array}{l}\text { El desorden provocado con los puestos ambulantes y comercios dificulta el tránsito a } \\
\text { través de sus calles. }\end{array}$ \\
\hline & $\begin{array}{l}\text { El tráfico vehicular desordenado genera contaminación ambiental e inclusive altera } \\
\text { emocionalmente a los visitantes. }\end{array}$ \\
\hline & $\begin{array}{l}\text { La inexistente información diseñada específicamente para visitantes incrementa la } \\
\text { sensación de desorden y complica la experiencia les cliente (turista). }\end{array}$ \\
\hline & $\begin{array}{l}\text { La inseguridad ciudadana se incrementa anualmente, tanto para paceños como para } \\
\text { visitantes nacionales y extranjeros. }\end{array}$ \\
\hline & Paralelamente se incrementa el consumo de bebidas alcohólicas \\
\hline & La intervención de productos ajenos a la región, que desplaza los productos típicos. \\
\hline $\begin{array}{l}\text { Comercio de } \\
\text { productos ajenos a la } \\
\text { región }\end{array}$ & $\begin{array}{l}\text { El mercado se rige por las fuerzas de la oferta y la demanda, es decir, los comerciantes } \\
\text { venden lo que genera mayores ingresos. }\end{array}$ \\
\hline \multirow[t]{2}{*}{ Falta de higiene } & $\begin{array}{l}\text { La población y los comerciantes incumplen normas de higiene básicas, en contra de la } \\
\text { atractividad de la zona. }\end{array}$ \\
\hline & Este aspecto se ve en la conducta de la población y de los comerciantes. \\
\hline \multirow[t]{2}{*}{$\begin{array}{l}\text { Falta de educación } \\
\text { turística }\end{array}$} & $\begin{array}{l}\text { En general la población no trata al turista con educación y respeto, coadyuvando al } \\
\text { desarrollo de una experiencia insatisfactoria y favoreciendo decremento del flujo } \\
\text { turístico mediante el marketing boca a boca negativo que se genera. }\end{array}$ \\
\hline & $\begin{array}{l}\text { Los comerciantes de trajes, artes y comidas entregan sus productos y servicios como } \\
\text { mercancías, menospreciando los recursos patrimoniales claves de la actividad turística. }\end{array}$ \\
\hline
\end{tabular}

Se identificaron cinco causas de problemas que afectan la preservación del $\mathrm{PCl}$ en la zona del Cementerio General, que son: desorden, inseguridad ciudadana, comercio de productos ajenos a la región, falta de higiene y falta de educación turística. En la segunda columna de la Tabla 3 se explica la problemática que se vive en la zona.

Todos estos factores influyen en que el patrimonio inmaterial de la zona no sea valorado por la población local ni por los visitantes. Se están perdiendo expresiones culturales con el paso del tiempo y es probable que su relevancia actual, la cual no es tan grande, sea aún inferior en un futuro.

\section{CONCLUSIONES}

En la zona del cementerio existe una gran variedad de riqueza cultural e inmaterial que, si bien va cambiando con el pasar de los años y la globalización, mantiene prácticas ancestrales, esta combinación se constituye en el $\mathrm{PCl}$ de la zona y de la ciudad. Sin embargo, se observa 
que los residentes de la zona asignan poca importancia a los esfuerzos de conservación de los bienes inmateriales presentes en el lugar, existe poco interés por fomentar este patrimonio. Este descuido no se da solo por los habitantes, sino también de los organismos públicos y privados (desde hace ya muy años), que no están realizando esfuerzos por potenciar estos como atractivo turístico y no implementan medidas para protegerlo adecuadamente.

La población paceña desconoce el significado amplio del patrimonio inmaterial y la importancia que este posee para potenciar un turismo que permanezca vigente a futuro. La valoración del patrimonio inmaterial es de suma importancia si se desea ampliar las fronteras del turismo hasta la zona de cementerio, no obstante, existen aspectos como el desorden comercial y geográfico, la inseguridad ciudadana y la evidente carencia de higiene en el entorno hacen que el flujo turístico haya disminuido en los últimos años.

Aunque estos tres ámbitos son los causantes principales para la insuficiente valoración del patrimonio inmaterial en la Zona del Cementerio, también es preciso señalar la carencia de información y promoción de este patrimonio. El poco conocimiento sobre el valor histórico, cultural y social de lo que se ofrece en la zona provoca que las personas no se apoderen de sus recursos inmateriales. De esta forma, su valoración queda en segundo plano y parte del $\mathrm{PCl}$ es vista como elementos para comercializar y generar ingresos, sin tomar en cuenta su atractividad hacia el desarrollo de la actividad turística de la zona.

El PCl debe ser gestionado de manera conjunta, entre la población local, las autoridades zonales, representaste del sector turístico y el Gobierno Municipal. Para esto es fundamental educar a la población en preservación del $\mathrm{PCl}$ y su importancia en el turismo. Sólo así se tomará conciencia sobre el valor turístico del patrimonio existente y serán los mismos ciudadanos los que serán promotores de su patrimonio cultural. De esta manera también se elevará la predisposición de brindar información al turista que actualmente afecta en la valoración de los recursos patrimoniales de la zona.

\section{REFERENCIAS}

Agencia de Noticias Fides. (1 de noviembre de 2019). La Paz: Cementerio General espera al menos 120 mil visitantes por la festividad de Todos Santos. ANF. https://www.noticiasfides. $\mathrm{com} /$ nacional/sociedad/cementerio-generalespera-al-menos-120-mil-visitantes-por-lafestividad-de-todos-santos-402090

Bolivia Fundación. (2014). El Cementerio General de La Paz alberga a más de 117 mil cuerpos. https://www.bolivia.com/cultura/noticias/ sdi/101975/el-cementerio-general-de-la-pazalberga-a-mas-de-117-mil-cuerpos

Cajías, F. (2016). Cincuenta años de gestión del patrimonio cultural en Bolivia. Universidad Católica Boliviana «San Pablo» [UCB]. La Paz, Bolivia

Diario La Razón. (2015). Lápidas: Espejos de la sociedad frenteala muerte.Suplemento Escape. http://www.la-razon.com/suplementos/ escape/Lapidas-espejos-sociedad-frentemuerte-escape_0_2372162865.html

GAMLP (2013). Gobierno Autónomo Municipal de La Paz. Cementerio General, el panteón de la ciudad de Nuestra Señora de La Paz. GAMLP. Oficialía Mayor de Culturas. La Paz, Bolivia

Hosteltur. (24 de septiembre de 2007). Los aspectos intangibles, clave del éxito del turismo urbano. https://www.hosteltur.com/46196_aspectosintangibles-clave-exito-turismo-urbano.html

La Época. (1 de noviembre de 2019). Festividad de «Todos Santos»: tradición que no muere y trasciende de generación en generación. https://www.la-epoca.com.bo/2019/11/01/ festividad-de-todos-santos-tradicion-queno-muere-y-trasciende-de-generacion-engeneracion/

Molano, O. (2007). Identidad cultural, un concepto que evoluciona. Opera. 7. Dialnet 
Navarro, D. (2015). Recursos turísticos y atractivos turísticos: conceptualización, clasificación y valoración. Universidad del Aconcagua. Argentina.

UNESCO. (2005). Organización de las Naciones Unidas para la Educación, la Ciencia y la Cultura. Convención sobre la protección y la promoción de la diversidad de las expresiones culturales

Paredes, N. (2012). La incidencia de la protección del patrimonio cultural inmaterial en la diversificación de la oferta turística. Caso: Fiesta Folklórica Jesús del Gran Poder. Universidad Mayor de San Andrés [UMSA]. La Paz, Bolivia

Pereira, R. (2008). Uso del espacio público en la ciudad de La Paz. Instituto de Investigaciones Sociológicas [IDIS]. Universidad Mayor de San Andrés [UMSA]. La Paz, Bolivia
Reuters (s.f.). Crónicas históricas y de cementerios. http://cronicasdecementerios.blogspot. com/2013/11/la-fiesta-de-la-natitas-enbolivia.html

Salazar, Y. (2018). «La casa de los pobres», templo de culto a las «ñatitas». Diario Correo del Sur. https://correodelsur.com/ panorama/20181111_la-casa-de-los-pobres-templo-de-culto-a-las-natitas.html

Urgentebo (5 de marzo de 2017). Despiden el carnaval con el entierro del pepino. https:// urgente.bo/noticia/despiden-el-carnaval-conel-entierro-del-pepino 